\title{
Editorial
}

\section{¿Qué dice el pueblo de la justicia y los derechos humanos en El Salvador?}

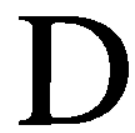

espués de transcurrir cuatro años desde la finma de los Acuerdos de Paz, ¿qué podemos decir de la Justicia y el respeto por los Derechos Huma nos en nuestro país?; surge la interrogante: ¿Se ha avanzado o ha habido retroceso en la consecución de estos objetivos después de finalizado el conflicto armado?

La respuesta a esta interrogante las encontramos en la última encuesta realizada por el Instituto de Opinión Pública de la Universidad Centroamericana "José Simeón Cañas", en la cual se exponen las opiniones de los salvadoreños respecto al sistema de justicia y los derechos humanos en nuestro país. Encuesta efectuada entre el 13 de julio y el 9 de agosto del presente año, con una muestra nacional de 1199 adultos de zonas urbanas y rurales de los catorce departamentos de la república.

¿Cuáles son los tópicos que trata la encuesta?

Podemos decir que recaen básicamente en dos aspectos:

I. La actuación de la Corle Suprema de Justicia con relación a sus decisiones, al control político y a la honestidad del sistema de justicia.

2. El estado actual del respeto de los derechos humanos vinculado a la institución de la Procuraduría para la Defensa de los Derechos Humanos.

Como observamos, se intenta evaluar a las dos instituciones precusoras de la democracia en El Salvador: la Corte Suprema de Justicia y la Procuraduría para la Defensa de los Derechos Humanos. 


\section{Corte Suprema de Justicia y el Sistema Judicial de EI Salvador}

Los salvadoreños y salvadoreñas. con relación a la Corte Suprema de Justicia, tienen una impresión favorable de la misma, ¿, será esto, muestra de una mayor credibilidad y satislacción hacia el trabajo de aquélla?

Las opiniones respecto a la satisfacción en la forma en que la Corte Suprema de Justicia ha eslado trabajando es variable: el $35.9 \%$ de los encuestados reflejan satisfacción; un $32.1 \%$ estan poco satisfechos y un $19.3 \%$ no estan nada satisfechos con la labor de la Corte. Pero podríamos decir que cerca del 40 por ciento de los consultados tienen una actitud favorable hacia ese organismo de Justicia.

Con relación a las resoluciones de la Corte Suprema de Justicia se evalúa, no la calidad jurídica de las decisiones, sino la esencia misma de ellas, como es la Justicia. Situación que está íntimamente relacionada con el control político ejercido sobre los jueces y con la propia honestidad del sistema de justicia en el pals.

Las opinioncs al respecto resultan negativas lamentablemente, ya que un $38.1 \%$ picnsan que el ináximo tribunal no emite sus fallos de manera justa; un $39.7 \%$ de los ciudadanos alirman que los jueces salvadoreños no toman en cuenla los puntos de vista de lodas las partes, antes de tomar una decisión; un $27 \%$ se mostraron indecisos o prefirieron no responder a la pregunta; un $57.4 \%$ opina que las personas que dirigen el país, realmente no estan preocupadas por lo que le sucede al ciudadano común; para el $60 \%$ de los encuestados, la mayoría de jucces están sujetos al control político, lo cual esta relacionado con el hecho de que el $58 \%$ de los consultados piensen que los funcionarios públicos no deberían acluar siguiendo los intereses del partido que los colocó en el puesto. Además, para concluir, a los encuestados se les pidió que identificarán lo que describe mejor al sistema de justicia salvadoreño, asignándole la característica de honesto o corruplo; al $47.1 \%$ les parece un sistema judicial comupto, mientras que una pequeña proporción, el $11.6 \%$ piensa que es honesto, pero hay un $32.1 \%$ que afirma que el sistema de justicia esta conformado por personas honestas así como por personas corruptas.

Todas cstas opiniones reflejan un sentimiento de inseguridad hacia la actuación de la Cortc Suprema de Justicia bastante real, tal como se demuestra con las respuestas a la pregunta siguiente: ¿Ya que el gobierno no proporciona justicia y scguridad, la gente liene el derecho de buscar la justicia por su propia mano? Un $46 \%$ piensa que se tiene el derecho a buscar la justicia por su propia mano; un $4.4 \%$ se mucstra indecisos; un $5.3 \%$ no responde; $y$, finalmente un $44.4 \%$ cstan en desacuerdo con esa postura.

\section{Los derechos humanos y la Procuraduría para la Defensa de los Derechos Humanos}

El tema del respeto por los derechos humanos es de suma importancia para 
los salvadoreños y salvadoreñas; es el derecho a la vida al que mayor protección debe darsele en la actualidad (23.6\%), en segundo lugar, son los derechos de los niños y niñas los que necesitan una atención urgente (21.4\%); y el bienestar social, que podramos interpretarlo como una necesidad de atención a los derechos económicos, sociales y culturales, ocupa un tercer lugar (8.9\%). De allí aparecen las libertades civiles, el respeto a la dignidad humana, protección a las minorlas minusválidas como derechos a proteger. Un punto alarmante es el hecho que el $23.4 \%$ no sabe qué derecho debe ser atendido con mayor urgencia actualmente; esto puede denotar dos realidades: $i$ Un desinterés por los derechos que posee y deben ser protegidos? o, ¿un total desconocimiento de lo que son los derechos y de cómo deben ser protegidos?. A nuestro parecer, es cuestión de educación y promoción en materia de derechos humanos y no de falta de interés, lo que explica este porcentaje.

Con relación a la actuación de la Procuradurfa para la Defensa de los Derechos Humanos, el $28.7 \%$ de los consultados piensa que es la institución que mejor defiende los derechos humanos a nivel nacional, al compararla con inslituciones como la Policia Nacional Civil, ONG's, Gobierno, Corte Suprema de Justicia, entre otras.

Pero a nivel de defensa de los derechos en la Comunidad, el 37.9\% piensa que ninguna institución protege sus derechos en su comunidad de vivienda; un $21.1 \%$ señala que la Policía Nacional Civil defiende sus derechos, y un $11.5 \%$ señala a la Procurduría para la Defensa de los Derechos Humanos. Además, un dato alarmante es que un $21.1 \%$ de los encuestados no sabe cuales son las instituciones que protegen sus derechos a nivel comunitario,. Esto nos indica la importancia de la labor que puedan realizar las instituciones gubernamentales y no gubernamentales en materia de promoción de derechos humanos.

Un dato positivo que demuestra la credibilidad hacia la labor de la Procuraduría para la Defensa de los Derechos Humanos, es la opinion favorable hacia el trabajo de la misma por parte de un $67.3 \%$ de los consultados; también el $53.9 \%$ evalúa como muy importante el trabajo de Procuraduría; un $37.4 \%$ lo evalúa como algo importante y sólo el $5 \%$ lo evalúa como nada importante; y finalmente, un $54.5 \%$ de los encuestados opinan que las declaraciones de la Procuraduría se dan de manera justa a la par de un $19.6 \%$ que cree que no son equilibradas sus declaraciones. Todo esto ubica a la Procuradurfa como una de las instituciones que mayor confianza dan a los ciudadanos salvadoreños, tal como se demuestra en la tabla de "Confianza en algunas Instituciones del país", que la ubican en un segundo lugar con un $21.7 \%$. Los noticieros televisivos y radiales así como la Policía Nacional Civil son otras de las instituciones que gozan de la confianza de la población salvadoreña.

En esta misma tabla, la Corte Suprema de Justicia aparece junto con la Fuerza Armada, la Asamblea Legislativa y el Gobiemo Central, como instituciones que no 
gozan de la confianza de los encuestados,.

Con todos estos elementos, proporcionados por la encuesta, podemos concluir que si bien ha habido avances en el tema del respeto a los derechos humanos y en el funcionamiento del sistema judicial, para la población salvadoreña todavia falta mucho por hacer. Es cierto que se ha avanzado en relación a la década pasada, pero en el presente se siguen percibiendo como viciadas las actuaciones y los procedimientos de la Corte Suprema de Justicia ya sea por el cáncer de la comupción o por la estrecha vinculación que existe con el poder político, lo cual agrava la desconfianza y la poca credibilidad hacia nuestro Sistema Judicial, que a la larga viene a mermar lodos los esfuerzos por encaminar a El Salvador hacia una real democracia.

Instiluciones como la Corte Suprema de Justicia y la Procuraduría para la Defensa de los Derechos Humanos deben ser las instituciones que más comprometidas deben estar con el cambio democrático; sus actuaciones deben demostrar su gran compromiso con la Justicia y el Derecho, para que los ciudadanos salvadoreños empiecen a cambiar su forma de percibir a estas instituciones y alejen de sus mentes la idea de tomar la justicia por sus propias manos, lo cual no favorece el desarrollo democrático y pacífico del pals. 